\title{
APPLYING THE SIGN LUMINANCE COMPUTATION MODEL TO STUDY THE EFFECTS OF OTHER VEHICLES ON SIGN LUMINANCE
}

\author{
Fan Ye ${ }^{1}$, Paul J. Carlson ${ }^{2}$, Bradford K. Brimley ${ }^{2}$ \\ ${ }^{1}$ Ohio Northern University, United States \\ ${ }^{2}$ Texas Transportation Institute, United States
}

Submitted 23 February 2013; resubmitted 26 March 2014; accepted 6 April 2014

\begin{abstract}
As one external lighting source on the road, headlamps from adjacent vehicles in the stream traffic should not be ignored. No comprehensive study has yet been developed for exploring the influence of sign luminance produced by other vehicle headlamps. In this paper, a luminance calculation model is developed to calculate sign luminance from all potential headlamps in the stream traffic. Using the model, four main scenarios have been simulated to analyze the effects of the positions of the target vehicle and other vehicles, vehicle type, sign type and sheeting material on the sign luminance. In addition, occlusion between vehicles is also addressed in the paper, by calculating the minimum distances between vehicles for the headlamps and for the driver's view of the following vehicle when vehicles and the sign are and are not in the same lane.
\end{abstract}

Keywords: sign luminance; luminance computation model; visibility; vehicle headlamp; occlusion.

Reference to this paper should be made as follows: Ye, F.; Carlson, P. J.; Brimley, B. K. 2014. Applying the sign luminance computation model to study the effects of other vehicles on sign luminance, Transport 29(2): 115-124.

http://dx.doi.org/10.3846/16484142.2014.927396

\section{Introduction}

A growing interest among transportation agencies across the U.S. has been determining when to light overhead guide signs (Ye et al. 2014). Lighting signs requires capital investment and continued maintenance. Besides the cost of lighting overhead guide signs, the growing interest to determine when sign lighting is needed follows the evolution of retroreflective sign sheeting materials. As retroreflective sign sheeting materials have become more efficient in returning headlamp illumination back to the driver, there has been a trend to turn off or remove most overhead guide sign lighting despite less overhead illuminance provided by vehicle headlamps, which was supported by the results of surveys of state transportation agencies (AASHTO 2011; A Review of KDOT... 2011). There is a general consensus that sign lighting is not needed in rural areas; but in developed areas or along highways with unique geometries, there is concern about removing or turning off overhead guide sign lights (Jackson et al. 2013). In addition, the influence of other external lighting to the signs should not be ignored, such as roadway lighting, ambient lighting and the headlamps from adjacent vehicles on the road.
In order to study whether sign lighting can be turned off, it is necessary to study the effects of all the available external lighting sources. The amount of sign luminance provided by sign lighting and roadway lighting is easier to be measured as they mostly provide diffuse lights to the sign, but it is harder to quantify the reflected lights from adjacent vehicle headlamps to the sign.

Meanwhile, previous research regarding sign brightness have mostly included one vehicle in the study, including those studies deriving the minimum required retroreflectivity in 2009 MUTCD - Manual on Uniform Traffic Control Devices (US DOT 2009). The luminance needed for elderly drivers to read guide signs at a distance coinciding with the requirements of the 2009 MUTCD (US DOT 2009) was based on the lighting from headlamps of one vehicle (Carlson, Hawkins 2003), ignoring the influence of other vehicle headlamps. In this study we evaluate the reflected light coming from other vehicles in the traffic. Only one relative study has been found, which indicated that sign luminance was enhanced by other vehicles on the road. Woltman and Youngblood (1976) investigated the effect of stream traffic on overhead signs by measuring the sign lumi- 
nance from low-beam headlamps in the stream traffic. Three reflective sheeting types were used in their study: encapsulated-lens, enclosed-lens and cube corner. Three densities of stream traffic were simulated by positioning three vehicles with $500 \mathrm{ft}(152.4 \mathrm{~m})$ spacing between cars, six vehicles with $300 \mathrm{ft}(91.4 \mathrm{~m})$ spacing and 15 vehicles with $50 \mathrm{ft}(15.2 \mathrm{~m})$ spacing. It was concluded from the study that sign luminance increased with the number of vehicles in the stream, though the change varied with the distance between driver and the sign. It was found that the illumination by stream traffic was more effective on overhead guide signs than ground-mounted signs. However, the study was done in 1976. At that time there was no high intensively reflective sheeting available, and the headlamps of vehicles were very different from current ones. Additionally, luminance measuring technology has changed significantly. Woltman and Youngblood (1976) set up to 15 vehicles in front of the target vehicle and measured the luminance of signs. But in their study, the scenarios were measured in the field and were limited. It could not cover various combinations of driver, headlamp and sign configurations. It is necessary to devote more effects studying the features of the additional sign luminance provided from other vehicles in various conditions, to help better understand how bright the sign can be in a realistic roadway and traffic situation, which helps decision makers to decide whether sign lighting is needed.

In this study, a computation tool is developed to calculate sign luminance from all potential headlamps in the stream traffic. It is hard to study the effects of some influencing factors that constantly change in the field. However, with the computation tool, we can simulate many scenarios and extract some patterns out of the calculated results by controlling some factors. The model that computes the additional sign luminance from other vehicles is discussed below, in a step-by-step process, followed by an analysis of the sign luminance from a target vehicle and other vehicles due to vehicle position and type and sign type. The occlusion of headlamps by other vehicles is also discussed. Finally, the significance of the findings is summarized in a conclusion.

\section{Luminance Computation Model}

The luminance computation model is an extension of Exact Roadway Geometry Output (ERGO), which was developed by Avery Dennison (Kleinschmit, Couzin 2008). In ERGO, the two headlamps of the driving vehicle are the only lighting sources for the sign luminance calculation. In the luminance computation model presented here, headlamps from other vehicles in the traffic stream are also counted as external lighting sources, but only the driver of a single 'target' vehicle is the target of the luminance calculated by the model. Since light possesses additive qualities, the luminance of a retroreflective sign from various lighting sources is also additive. Therefore, by using the model, it is possible to investigate the effects of other vehicles on sign visibility under various scenarios. The calculation procedures are listed in Fig. 1 and explained step by step in this section.

\section{Step 1}

First, input the geometries of the four elements into the luminance computation model: target vehicle, roadway, sign and other vehicles, as listed in Table 1. Accordingly, the driving system has been defined in Cartesian coordinates based on the relative positions of the four elements.

\section{Step 2}

Using the results of Step 1, the illumination distance $\left(d_{I}\right)$, which is the distance between each headlamp and sign, and the viewing distance $\left(d_{V}\right)$, which is the distance between the driver and sign, can be calculated in Cartesian coordinates in Steps 2.3 and 2.5, respectively (as shown in Fig. 1). Furthermore, using the vector mathematics described by Johnson (1999), the driving system in the Cartesian coordinates can be transformed into the angular system. Therefore, some angles needed in the model are ready to be calculated.

The retroreflectivity of sign sheeting is dependent on its angularity in the application system, which includes: observation angle $(\alpha)$, entrance angle $(\beta)$, rotation angle $(\varepsilon)$ and orientation angle $\left(\omega_{s}\right)$. Fig. 2 (Brich 2002) depicts the interrelationship of these angles which are needed for obtaining the coefficient of retroreflection $\left(R_{a}\right)$ of sign sheeting. They are calculated in Step 2.1 for each headlamp of each vehicle in the traffic with the driver of the target vehicle always being the receiver.

Luminous intensity $(I)$ of a vehicle headlamp changes based on its horizontal and vertical angles to the sign. Therefore, in Step 2.2, the angles of both vehicle headlamps are calculated in the angular system. In step 2.4 , the viewing angle of the driver is calculated. Viewing angle $(\mathrm{v})$ is the angle between the driver's line of sight to the sign and retroreflector axis, which is normal to the sign surface (see Fig. 2). Viewing angle will be used in the calculation of the luminance.

\section{Step 3}

There are two external databases for the luminance computation model. One includes the retroreflectivity matrices for all types of sheeting and the other includes luminous intensity matrices to accommodate different headlamp profiles. For the retroreflectivity matrices, except those attained from the ERGO model, newer sheeting types have been added to the database with the measurements taken in the Stimsonite lab, including ASTM IV, IX and XI sheeting materials (ASTM D4956-13). Once a specific sign sheeting type is selected in Step 3.1, its retroreflectivity matrices are ready to calculate the coefficient of retroreflection.

Within the last 10 years, headlamps have evolved and their performances have improved steadily and the headlamp profiles in the ERGO model are outdated (Jackson et al. 2013). Therefore, a recent headlamp profile is included in the model: US2011, which is the 50th percentile of the U.S. low beam bulbs' photometric table and was measured in 2011 (Schoettle, Flannagan 2011). 


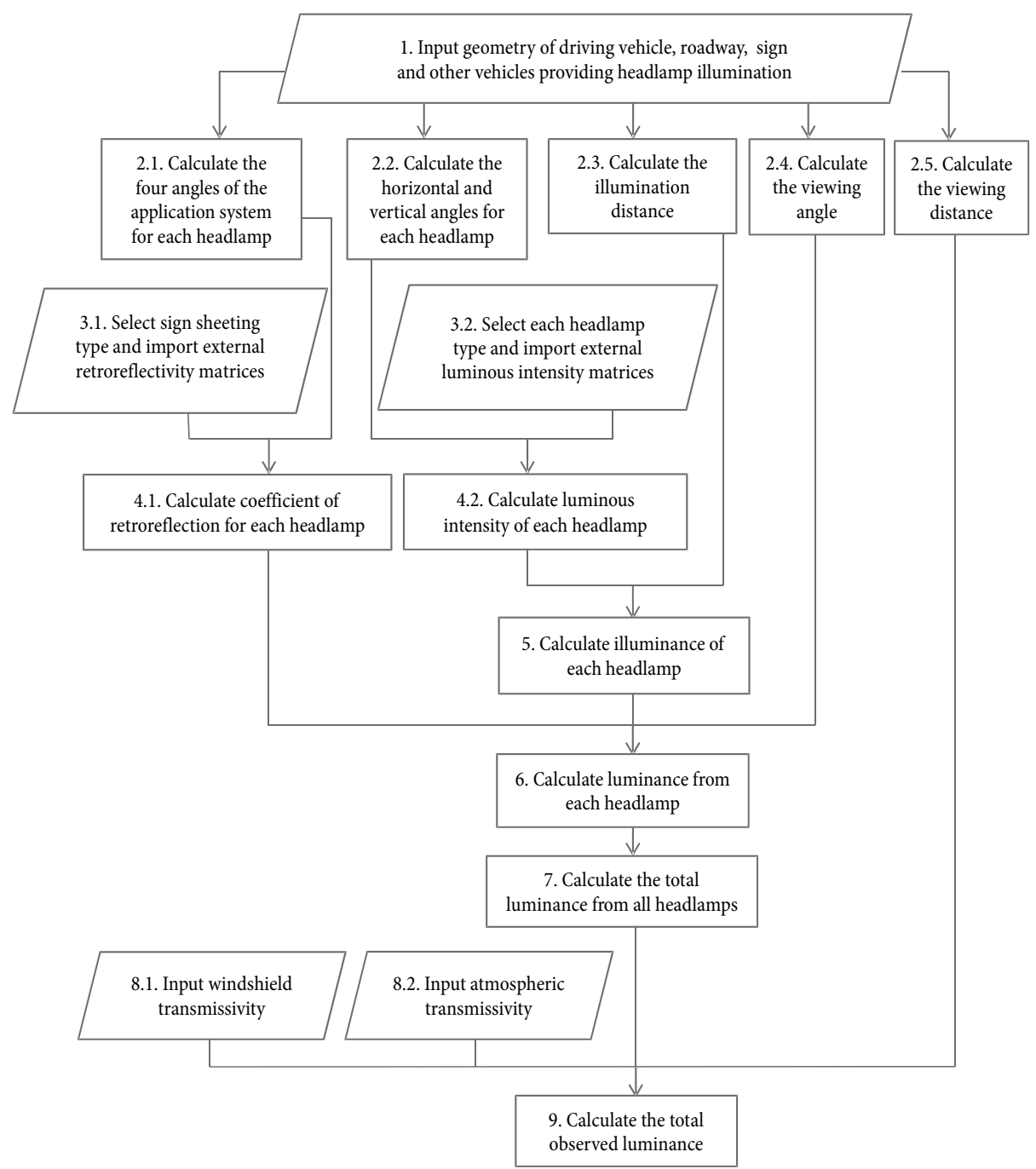

Fig. 1. Flow chart of calculation procedures in the luminance computation model

Table 1. Geometry inputs of the luminance computation model

\begin{tabular}{|c|c|c|c|c|c|}
\hline Element & \multicolumn{5}{|c|}{ Geometry input } \\
\hline Target vehicle & $\begin{array}{l}\text { Distance between } \\
\text { headlights }\end{array}$ & $\begin{array}{l}\text { Headlamp height } \\
\text { above road }\end{array}$ & $\begin{array}{l}\text { Eye height } \\
\text { above road }\end{array}$ & $\begin{array}{l}\text { Eye setback from } \\
\text { headlamps }\end{array}$ & $\begin{array}{l}\text { Eye distance left of vehicle } \\
\text { center-line }\end{array}$ \\
\hline Roadway & Lane width & $\begin{array}{l}\text { Total number } \\
\text { of lanes }\end{array}$ & $\begin{array}{l}\text { Lane number of } \\
\text { driving vehicle }\end{array}$ & $\begin{array}{l}\text { Horizontal/vertical } \\
\text { curvature and length }\end{array}$ & $\begin{array}{l}\text { Distance from the front of } \\
\text { driving vehicle to the sign }\end{array}$ \\
\hline Sign & $\begin{array}{l}\text { Sign offset to the } \\
\text { edge of driving lane }\end{array}$ & Sign height & & & \\
\hline $\begin{array}{l}\text { Other vehicles } \\
\text { providing } \\
\text { illumination }\end{array}$ & $\begin{array}{l}\text { Distance between } \\
\text { headlamps }\end{array}$ & $\begin{array}{l}\text { Headlamp height } \\
\text { above road }\end{array}$ & $\begin{array}{l}\text { Longitudinal } \\
\text { distance from } \\
\text { the sign }\end{array}$ & $\begin{array}{l}\text { Lane number of } \\
\text { vehicles (in place of } \\
\text { lateral distance) }\end{array}$ & \\
\hline
\end{tabular}

\section{Step 4}

Using the results of Steps 2.1 and 3.1, the coefficient of retroreflection $\left(R_{a}\right)$ for each headlamp can be obtained by using a multipoint quadratic lookup and interpolation feature, in Step 4.1. In other words, find the closest value of $R_{a}$ for each headlamp in the retroreflectivity matrices by the calculated $\alpha, \beta, \varepsilon$ and $\omega_{s}$. Using the results of Steps 2.2 and 3.2, luminous intensity (I) of each headlamp can be found in the luminous intensity matrices of its type by the calculated horizontal and vertical headlamp angles to the sign, in Step 4.2. A two-way quadratic lookup and interpolation feature is used. 


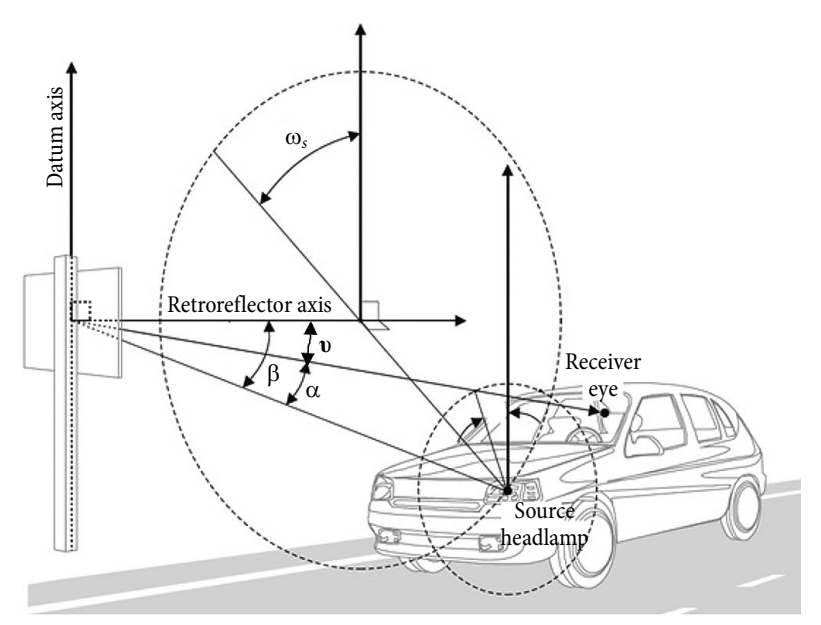

Fig. 2. The interrelationship of the angles in the application system (Brich 2002)

\section{Step 5}

Based on the results of Steps 2.3 and 4.2, the illuminance (E) from each headlamp is calculated by Equation (1), which is known as the Inverse Square Law (ISL) (Carlson, Hawkins 2003):

$$
E=\frac{I}{d_{I}^{2}},
$$

where: $E$ is the illuminance $[\mathrm{lx}] ; d_{I}$ is the distance between each headlamp and sign $[\mathrm{m}] ; I$ is the luminous intensity $[\mathrm{cd}]$.

\section{Step 6}

Combining the results of Steps 4.1, 2.4 and 5, the supply luminance $(L)$ of a retroreflective sign from each headlamp, directed toward the driver, is estimated using Equation (2):

$$
L=\frac{R_{a} \cdot E}{\cos (v)},
$$

where: $R_{a}$ is the coefficient of retroreflection of the sign corresponding to each headlamp of each vehicle in the steam traffic, with the target driver as the observation point, and $v$ is the viewing angle for the sign.

\section{Step 7}

Due to the additive characteristics of luminance supplied by different lighting, the total luminance of a sign $\left(L_{\text {sum }}\right)$ is the sum of luminance from each headlamp in the traffic. Step 7 is calculating $L_{\text {sum }}$ based on each headlamp luminance in Step 6.

\section{Step 8}

The above calculation of luminance does not consider any obstacles between the sign and the driver. However, the driving environment is not perfect and there are at least two adjustment factors to account for: windshield transmissivity and atmospheric transmissivity (Carlson, Hawkins 2003). Light traveling from the sign to the driver is partially absorbed by the vehicle windshield before it reaches the driver's eyes. The windshield transmissivity factor $\left(F_{w}\right)$ is a multiplicative effect between 0 and 1 used to adjust the luminance. It was found that a typical value for windshield transmissivity is 0.72 (Carlson, Hawkins 2003). The input of windshield transmissivity is required in Step 8.1. In addition, light is scattered by particles in the air, which also reduces the luminance depending on the weather and the viewing distance. This is described by the atmospheric transmissivity factor $\left(F_{a}\right)$. An atmospheric transmissivity of $0.86 \mathrm{~km}^{-1}$ (Carlson, Hawkins 2003) was used to represent a typical dry condition. The value is identified in Step 8.2.

\section{Step 9}

Step 9 is to calculate the total observed luminance is by Equation (3):

$$
L_{\text {obs }}=L_{\text {sum }} \cdot F_{w} \cdot F_{a} \cdot d_{V},
$$

where: $L_{o b s}$ is the observed luminance; $L_{\text {sum }}$ is the ideal luminance from all headlamps in the traffic; $F_{w}$ is the windshield transmissivity factor; $F_{a}$ is the atmospheric transmissivity factor; $d_{V}$ is the viewing distance.

\section{Model Design and Analysis}

With the steps of the model described, the model can analyze the effects of other vehicle headlamps on sign luminance at the perspective of the driver in the target vehicle, in terms of different sign-vehicle geometry, sign type, sheeting material and vehicle type. In this paper, some typical situations are selected for these factors. Two types of signs are included in the analysis: overhead guide signs and street-name signs. For overhead signs, the height of the sign (from the center of the sign to the ground) is assumed to be $23 \mathrm{ft}(7.0 \mathrm{~m})$, and the sign is above the middle of a driving lane. For streetname signs, sign height is assumed to be $10 \mathrm{ft}(3.0 \mathrm{~m})$, and the sign is on the right side of driving lane with $6 \mathrm{ft}$ $(1.8 \mathrm{~m})$ offset from the right edge of the driving lane to the center of the sign. Also, based on typical legend sizes and the legibility demands by drivers, a distance range between $200 \mathrm{ft}(61.0 \mathrm{~m})$ and $700 \mathrm{ft}(213.4 \mathrm{~m})$ (with $100 \mathrm{ft}$ or $30.5 \mathrm{~m}$ intervals) is assumed for overhead guide signs, and $50 \mathrm{ft}(15.2 \mathrm{~m})$ to $300 \mathrm{ft}(91.4 \mathrm{~m})$ (with $50 \mathrm{ft}$ or $15.2 \mathrm{~m}$ intervals) for street name signs.

In addition, two vehicle types are included in the study: a passenger car and a truck or Sport Utility Vehicle (SUV). Their dimensions are listed in Table 2 (Carlson, Hawkins 2003). Two types of sheeting materials are used in the study: ASTM XI which is a relatively new type of prismatic sheeting, and ASTM III which is a beaded material. Lane width is set as $12 \mathrm{ft}(3.7 \mathrm{~m})$, the vehicle is always driving in the middle of a lane, and vehicle headlamps are US2011.

\section{Effect of Target Vehicle Position}

Before studying the effects of other vehicle headlamps on sign luminance, we first check the effect of the relative lateral position of the vehicle and the sign. In this study, the overhead guide sign contains Type XI sheeting 
Table 2. Vehicle dimensions

\begin{tabular}{l|c|c|c|c|c|c|c|c}
\hline Vehicle description & $\begin{array}{c}\text { Headlamp } \\
\text { height }\end{array}$ & $\begin{array}{c}\text { Driver's eye } \\
\text { height }\end{array}$ & $\begin{array}{c}\text { Headlamp } \\
\text { separation }\end{array}$ & $\begin{array}{c}\text { Driver's eye } \\
\text { setback }\end{array}$ & $\begin{array}{c}\text { Driver's eye } \\
\text { offset }\end{array}$ & $\begin{array}{c}\text { Length of } \\
\text { vehicle }\end{array}$ & $\begin{array}{c}\text { Height of } \\
\text { vehicle }\end{array}$ & $\begin{array}{c}\text { Width of } \\
\text { vehicle }\end{array}$ \\
\hline Passenger car [ft (m)] & $2.0(0.6)$ & $3.5(1.1)$ & $4.0(1.2)$ & $4.5(1.4)$ & $1.5(0.5)$ & $12(3.7)$ & $5(1.5)$ & $6(1.8)$ \\
\hline Truck/SUV [ft $(\mathrm{m})]$ & $2.8(0.9)$ & $4.8(1.5)$ & $4.4(1.3)$ & $7.2(2.2)$ & $1.3(0.4)$ & $15(4.6)$ & $6(1.8)$ & $7(2.1)$ \\
\hline
\end{tabular}

and is mounted in the center of the middle of five lanes, as shown in Fig. 3. The target vehicle is a passenger car.

By running the luminance calculation model, sign luminance is calculated for a passenger car driving between $200 \mathrm{ft}(61.0 \mathrm{~m})$ and $700 \mathrm{ft}(213.4 \mathrm{~m})$ from the overhead guide sign, within any of the five lanes. The outputs are summarized in Fig. 4.

From Fig. 4, when a vehicle approaches the overhead sign, the sign luminance produced by its own headlamps first increases and then decreases, with the inflection point near $300 \mathrm{ft}(91.4 \mathrm{~m})$ between the vehicle and the sign. This is reasonable because luminance is countered by two main factors: observation angle and headlamp illumination. Increased observation angles and decreased headlamp illumination lead to decreased luminance. When driving distance changes, the observation angle changes and the sign is located at a different spot of the headlamp illumination pattern. Therefore,

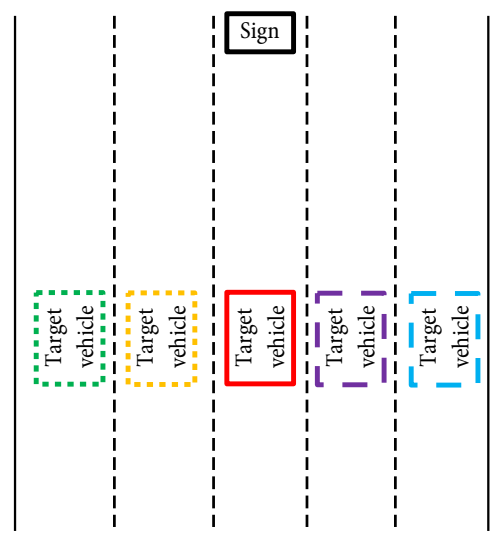

Fig. 3. Overhead view of vehicle-sign placement

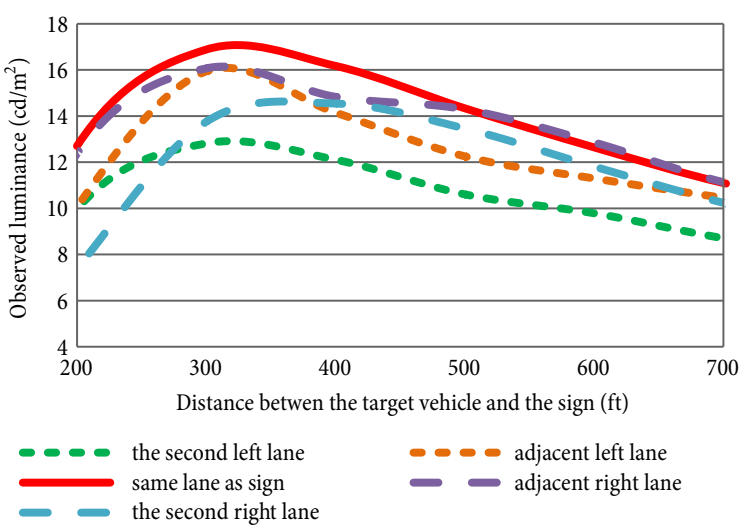

Fig. 4. Sign luminance vs. driving distance for a vehicle in different lane the relationship between luminance and driving distance relies on both the sign-vehicle geometry and headlamp characteristics.

Fig. 4 shows that the change of luminance is not large when the vehicle switches to another lane, indicating that the effect of driving lane position on an overhead sign is small. However, luminance is slightly larger when the vehicle and the sign are in the same lane. Using that luminance as the baseline, the average percentages of luminance when the vehicle is in the adjacent left lane, adjacent right lane, second left lane, and second right lane are $88 \%, 98 \%, 76 \%$, and $85 \%$, respectively.

\section{Effect of Other Vehicle Position}

It has been noticed that sign luminance does not change substantially when the target vehicle switches lanes. For this evaluation, the target vehicle is assumed to be located in the same lane as the sign mounted overhead. Another vehicle which contributes external light is located at $0 \mathrm{ft}(0 \mathrm{~m})$ (only if it is not in the same lane as the target vehicle), $100 \mathrm{ft}(30.5 \mathrm{~m}), 150 \mathrm{ft}(45.7 \mathrm{~m})$ or $200 \mathrm{ft}$ $(61.0 \mathrm{~m})$ in front of/behind the target vehicle. In order to check the effect of relative lateral placement of the other vehicle on sign luminance, the other vehicle is located in the same, adjacent right, or adjacent left lane as the target vehicle, as shown in Fig. 5. For simplicity, only three lanes are shown in the Fig. 5. Type XI sheeting and passenger cars are used with the same parameters as above.

Fig. 6 shows the results of the luminance calculation model. From Fig. 6, it is clear that other vehicle headlamps add more luminance to the sign, though the amount varies with the relative position of the target vehicle and the other vehicle. At a fixed driving distance between the target vehicle and the sign, the vehicle in the same lane as the target vehicle adds much more lu- a)

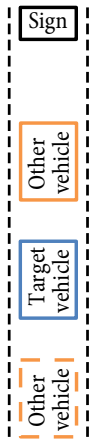

b)

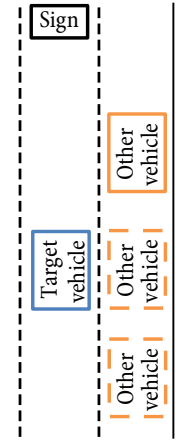

c)

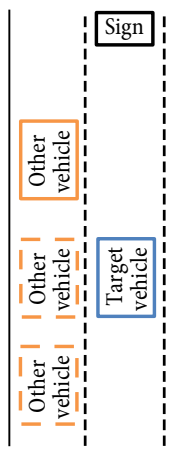

Fig. 5. Overhead view of vehicles-sign placement 
minance than those in the other lanes. With greater distance between the sign and the target vehicle, the other vehicle makes a greater contribution to the luminance. The percentage of luminance from the other vehicle to that from the target vehicle is calculated when both vehicles are in the same lane. When the target vehicle is at least $400 \mathrm{ft}(121.9 \mathrm{~m})$ from sign, another vehicle which is $100 \mathrm{ft}(30.5 \mathrm{~m})$ behind the target vehicle increases the sign luminance by nearly $50 \%$. At a distance of $700 \mathrm{ft}$ $(213.4 \mathrm{~m})$, a vehicle $100 \mathrm{ft}(30.5 \mathrm{~m})$ in front of the target vehicle can increase the sign luminance by about $80 \%$.

The closer the other vehicle is to the target vehicle, the more sign luminance adds due to a smaller observation angle. Another interesting finding from Fig. 6 is that, generally, larger luminance is added by a vehicle behind the target vehicle than a vehicle in front of it at the same distance. It is especially obvious when the additional vehicle is in the same lane as the target vehicle.

a)

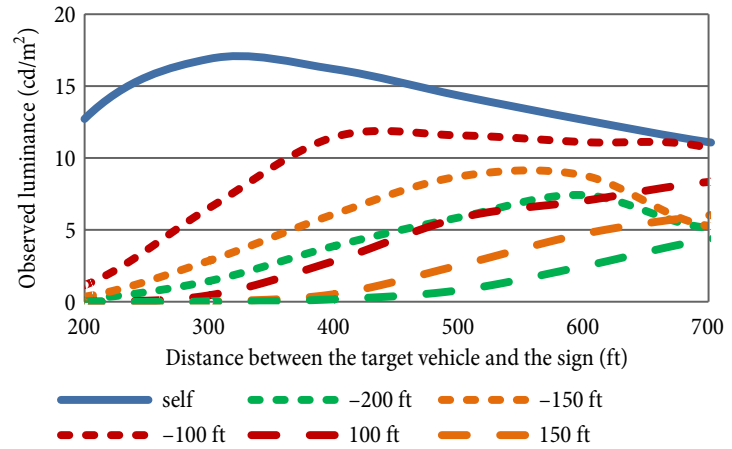

b)

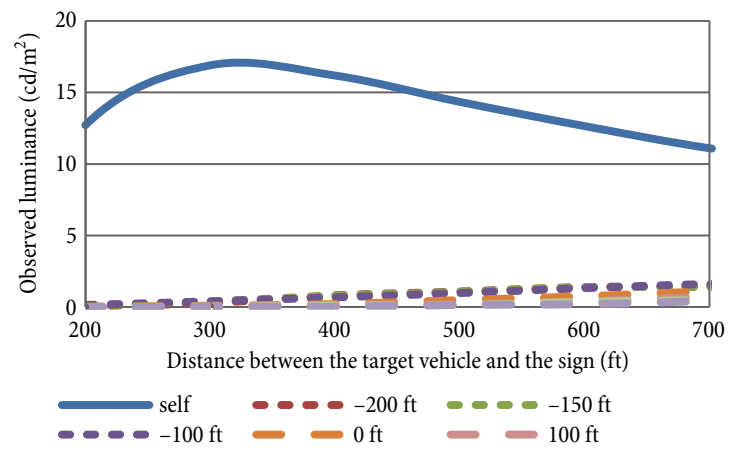

c)

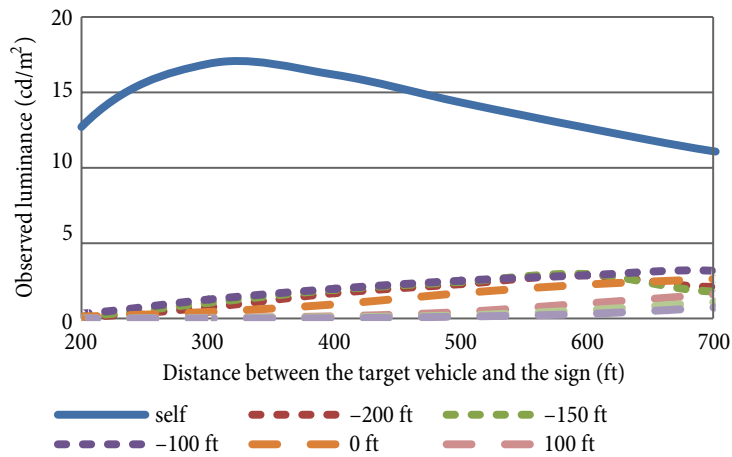

Fig. 6. Sign luminance when: a - both vehicles in the same lane; $\mathrm{b}$ - other vehicle in the right lane to the target vehicle; $\mathrm{c}$ - other vehicle in the left lane to the target vehicle

\section{Effect of Vehicle Type}

We have seen that headlamps from another vehicle increase sign luminance depending on the relative positions of the vehicle, target vehicle and sign. In this section, vehicle type is included in the study to explore the other vehicle's influence on sign luminance, with the same factors as those above fixed. There are four combinations based on the type of target vehicle and other vehicle: car-car, SUV-SUV, car-SUV, and SUV-car. The other vehicle is set as $100 \mathrm{ft}(30.5 \mathrm{~m})$ in front of the target vehicle in the same lane. The outputs are summarized in Fig. 7a. For instance, car-SUV 100 in Fig. 7a refers to a truck/SUV $100 \mathrm{ft}(30.5 \mathrm{~m})$ in front of a passenger car which is the target vehicle.

In Fig. 7a, the sign luminance produced by headlamps of a target vehicle (either a car or SUV) is larger than that from headlamps of the other vehicle. The or-

a)

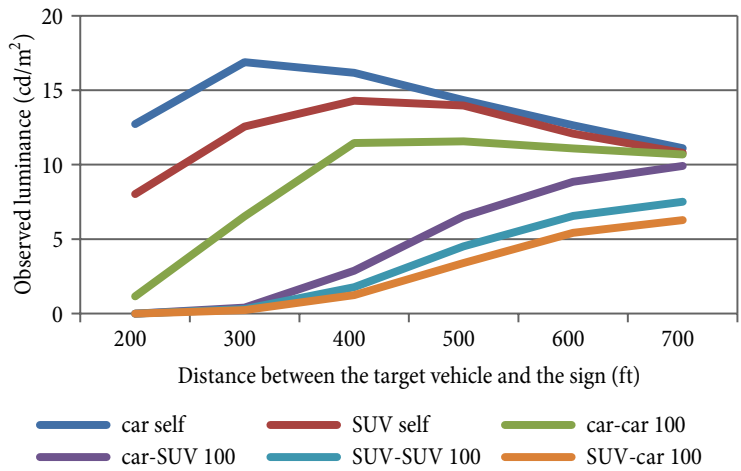

b)

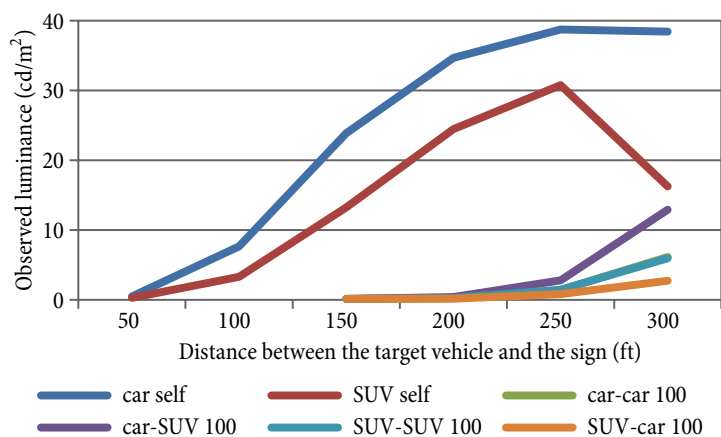

c)

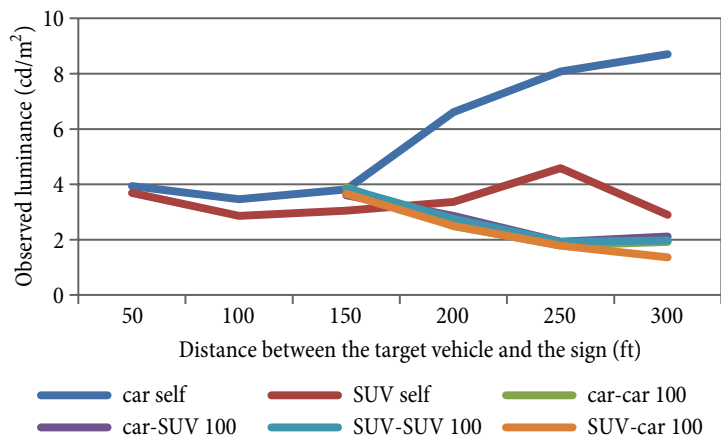

Fig. 7. Luminance for different vehicle type combinations: $\mathrm{a}$ - overhead guide sign with sheeting Type as XI; b - streetname with sign sheeting Type as XI; c - street-name sign with Sheeting Type as III 
der of producing sign luminance from the largest to the smallest is: car-self, SUV-self, car-car 100, car-SUV 100, SUV-SUV 100, SUV-car 100. For trucks and SUVs, the driver's eyes are placed higher from the headlamps than for passenger cars, which results in a bigger observation angle and less light retroreflected by the sign. However, headlamps on trucks and SUVs are higher, leading to a larger amount of light that can be projected to overhead signs. Therefore, the luminance is a trade-off between the vertical difference between the headlamps and the driver's eyes, and the mounting height of headlamps.

\section{Effect of Sign Type and Sheeting Material}

The above analysis is based on overhead guide signs. In this section, in order to check the effects of sign placement and sheeting material on the luminance produced by the headlamps of the target vehicle or other vehicle, similar analysis is done for a typical street-name sign with ASTM Types XI and III sheeting. The results are shown in Figs $7 \mathrm{~b}$ and $7 \mathrm{c}$ for Types XI and III sheeting, respectively. Comparing Figs $7 \mathrm{~b}$ and $7 \mathrm{c}$ with Fig. $7 \mathrm{a}$, the order of sign luminance provided is similar for overhead guide signs and street-name signs in the range of the interested distance. However, the other vehicle has less effect on sign luminance for street-name signs than for overhead guide signs. Additionally, car-car 100 adds almost the same sign luminance as SUV-SUV 100 for street-name signs, which probably results from the similar observation angles of the scenarios.

\section{Occlusion Model}

In the above analysis, it is assumed that the leading vehicle is not blocking either the light or the driver's view of the following vehicle no matter whether they are in the same lane or not. However, occlusion occurs with closely spaced vehicles. A vehicle can occlude the other behind or to the side of it depending on the sign placement. For simplicity, occlusion with the leading and following vehicles in the same lane is discussed in the paper. It needs to be pointed out that only the target vehicle as a following vehicle is discussed in the paper. When the target vehicle becomes the leading vehicle, the analysis is similar but there is no occlusion for the driver's view, only the potential occlusion of the headlamps of the other following vehicle.

\section{Occlusion when Vehicles and Sign in the Same Lane}

The simplest occlusion exists when the sign (i.e., overhead guide sign in the study) is placed directly in front of the approaching vehicles. Given sign height $H$, distance of the target vehicle (i.e., following vehicle) to the sign $D$, the length of occluding vehicle $L$, headlamp height $\left(h_{H}\right)$, driver's eye height $\left(h_{E}\right)$, driver's eye offset $\left(D_{s}\right)$ of the target vehicle, we can use geometry to determine the minimum gap between the two vehicles, as shown in Fig. 8.

If the gap between vehicles is less than $G_{\text {Emin }}$, the view of the driver in the target vehicle is blocked by the

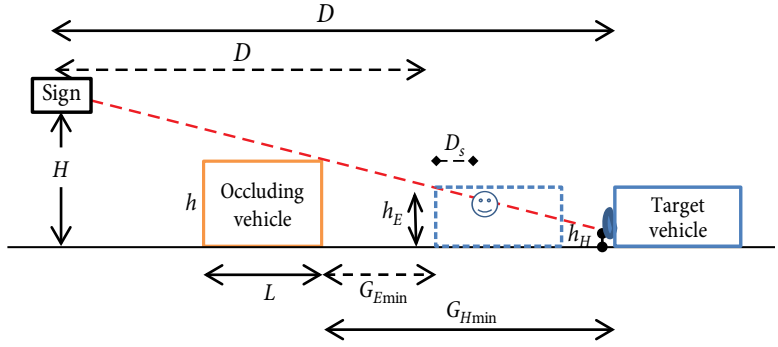

Fig. 8. Roadside view of geometry when vehicles and sign in the same lane

occluding vehicle and the driver cannot see the sign. If the gap between vehicles is between $G_{\text {Emin }}$ and $G_{H \text { min }}$, then headlights of the target vehicle cannot reach the sign and drivers in the target vehicle needs to rely on the other lighting sources (such as the headlights of the occluding vehicle) to see the sign. According to Fig. 8, $G_{E \min }$ and $G_{H \min }$ can be determined by the geometry as shown in Equations (4) and (5):

$$
\begin{aligned}
& \frac{G_{H \min }}{D}=\frac{h-h_{H}}{H-h_{H}} ; \\
& \frac{G_{E \min }+D_{s}}{D+D_{s}}=\frac{h-h_{E}}{H-h_{E}} .
\end{aligned}
$$

Accordingly,

$$
\begin{aligned}
G_{H \min } & =\frac{h-h_{H}}{H-h_{H}} \cdot D ; \\
G_{E \min } & =\frac{h-h_{E}}{H-h_{E}} \cdot\left(D+D_{s}\right)-D_{s} .
\end{aligned}
$$

Since the distance between two vehicles in the luminance calculation model refers to the headway distance, the minimum distance between the vehicles is the sum of the minimum gap and length of occluding vehicle. Therefore:

$$
\begin{aligned}
D_{H \min } & =\frac{h-h_{H}}{H-h_{H}} \cdot D+L ; \\
D_{\text {Emin }} & =\frac{h-h_{E}}{H-h_{E}} \cdot\left(D+D_{s}\right)-D_{s}+L,
\end{aligned}
$$

where: $D_{H \min }$ is the minimum distance between vehicles for the headlamps of the following vehicle reaching the sign; $D_{E m i n}$ is the minimum distance between vehicles for the driver in the following vehicle to see the sign; all the other parameters are as defined before.

Based on the vehicle dimensions defined in Table 2, $D_{H \text { min }}$ and $D_{E \text { min }}$ can be calculated for different vehicle types at various driving distances. The results are summarized in Table 3 for overhead guide signs. It can be seen that as the target vehicle approaches the guide sign, less minimum distance for headlamps and driver's view is needed. In addition, when a truck/SUV is followed by a car (car-SUV) both $D_{\text {Hmin }}$ and $D_{\text {Emin }}$ have the largest values, while the smallest values are attained for SUVcar. It is expected that more distance between vehicles is needed to avoid occlusion when a small vehicle is following a big vehicle. 


\section{Occlusion when Vehicles and Sign not in the Same Lane}

When vehicles and the sign are not in the same lane, we use geometry shown in Fig. 9 to determine the minimum gap between the two vehicles. In Fig. 9, $S_{H}$ is the headlamp separation of the target vehicle; $W_{l n}$ is the width of lane; $O_{s}$ is the right offset of the sign from the edge of driving lane; $W_{v}$ is the width of the occluding vehicle; $L$ is the length of the occluding vehicle; $D$ is the distance between the target vehicle and the sign; $O_{E}$ is the driver's eye offset in the target vehicle; $D_{s}$ is the driver's eye setback in the target vehicle.

According to the geometry shown in Fig. 9, $G_{E \min }$ and $G_{H \min }$ can be determined by Equations (10) and (11):

$$
\begin{gathered}
\frac{G_{H \min }}{D}=\frac{\frac{S_{H}}{2}+\frac{W_{v}}{2}}{\frac{S_{H}}{2}+\frac{W_{l n}}{2}+O_{s}} ; \\
\frac{G_{E \min }+D_{s}}{D+D_{s}}=\frac{O_{E}+\frac{W_{v}}{2}}{O_{E}+\frac{W_{l n}}{2}+O_{s}} .
\end{gathered}
$$

Similar to Equations (8) and (9), $D_{H \text { min }}$ and $D_{\text {Emin }}$ for a condition when the vehicles and the sign are not in the same lane can be calculated by Equations (12) and (13):

$$
\begin{aligned}
& D_{H \min }=\frac{\frac{S_{H}}{2}+\frac{W_{v}}{2}}{\frac{S_{H}}{2}+\frac{W_{l n}}{2}+O_{s}} \cdot D+L ; \\
& D_{E \min }=\frac{O_{E}+\frac{W_{v}}{2}}{O_{E}+\frac{W_{l n}}{2}+O_{s}} \cdot\left(D+D_{s}\right)-D_{s}+L .
\end{aligned}
$$
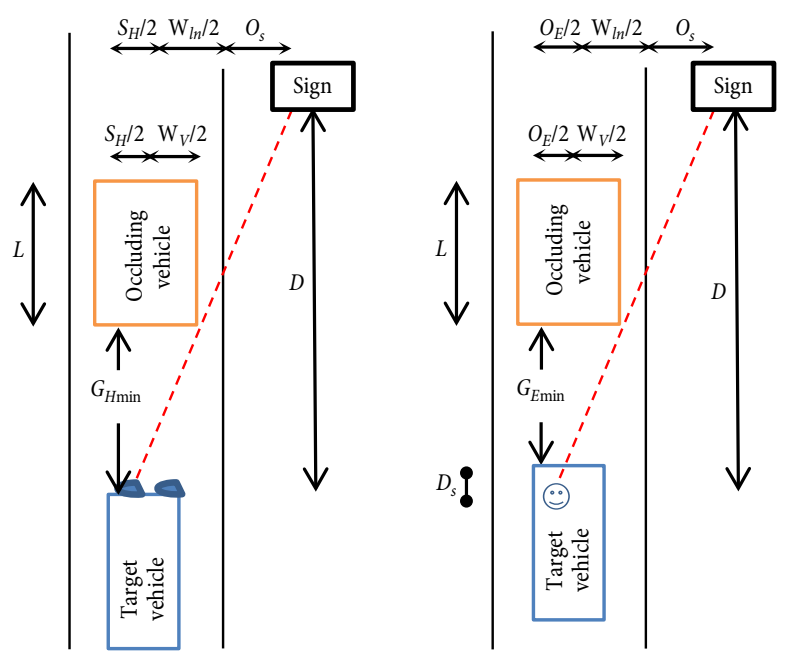

Fig. 9. Overhead view of geometry when vehicles and sign not in the same lane: a - to calculate the minimum gap for headlamps; $b$ - to calculate the minimum gap for viewing
As an example, occlusion distances for street-name signs are given in Table 3. From Table 3 for street-name signs, as the target vehicle approaches the sign, minimum occlusion distances decrease for headlight and driver's view which is consistent with the finding from overhead guide signs. However, for street-name signs, the difference between the minimum occlusion distances for different vehicle types is not as large as that of overhead guide signs.

According to the numbers in Table 3, occlusion was ignored for some situations in the analysis we have done, since the designed headway distances (100 ft or $30.5 \mathrm{~m}$ for overhead guide signs and $50 \mathrm{ft}$ or $15.2 \mathrm{~m}$ for streetname signs) are smaller than some of the numbers in the Table 3. As the analysis before is for demonstration purpose only, no further discussion will be made in the paper about the occlusion.

\section{Conclusions}

Supplying illumination to the signs, the headlamps from adjacent vehicles in the stream traffic should not be ignored. However, except for a field study developed over thirty years ago, no other research has been done for exploring the influence of other vehicle headlamps on sign luminance. In this paper, a computation tool, named the luminance calculation model, is developed to calculate sign luminance from all potential headlamps in the stream traffic. Using the model, four main scenarios have been simulated to analyze the effects of the position of the target vehicle and other vehicle, vehicle type, sign type and sheeting material on the sign luminance.

The effect of target vehicle position on overhead guide sign luminance is first examined. It is found that the relationship between luminance and driving distance is not consistent, relying on both the sign-vehicle geometry and headlamp characteristics. Meanwhile, the change of luminance is not large when the vehicle switches to another lane.

For the effect of other vehicles on sign luminance, it is clear that other vehicle headlamps add more luminance to the sign especially when the additional vehicle is in the same lane as the target vehicle, though the amount varies with the relative position of the target vehicle and the other vehicle. With greater distance between the sign and the target vehicle, the other vehicle makes a greater contribution to the luminance. It is also noticed that the closer the other vehicle is to the target vehicle, the more sign luminance gets added. Furthermore, more luminance is added by a vehicle behind the target vehicle than a vehicle in front of it at the same distance from the sign.

In terms of the influence of vehicle type on sign luminance, the sign luminance produced by headlamps of a target vehicle is larger than that from headlamps of the other vehicle when the target vehicle is a passenger car. Also, the luminance is a trade-off between the vertical 
Table 3. The minimum distances for avoiding occlusion

\begin{tabular}{|c|c|c|c|c|c|c|c|}
\hline \multicolumn{8}{|c|}{ Overhead guide signs } \\
\hline \multicolumn{2}{|c|}{ Driving distance of target vehicle $[\mathrm{ft}(\mathrm{m})]$} & $200(61.0)$ & $300(91.4)$ & $400(121.9)$ & $500(152.4)$ & $600(182.9)$ & $700(213.4)$ \\
\hline \multirow{2}{*}{ Car-car } & $D_{\text {Hmin }}$ & $41(12.5)$ & $55(16.8)$ & $69(21.0)$ & $83(25.3)$ & $98(29.9)$ & $112(34.1)$ \\
\hline & $D_{\text {Emin }}$ & $23(7.0)$ & $31(9.4)$ & $39(11.9)$ & $46(14.0)$ & $54(16.5)$ & $62(18.9)$ \\
\hline \multirow{2}{*}{ Car-SUV } & $D_{\text {Hmin }}$ & $53(16.2)$ & $72(21.9)$ & $91(27.7)$ & $110(33.5)$ & $129(39.3)$ & $148(45.1)$ \\
\hline & $D_{\text {Emin }}$ & $37(11.3)$ & $50(15.2)$ & $62(18.9)$ & $75(22.9)$ & $88(26.8)$ & $101(30.8)$ \\
\hline \multirow{2}{*}{ SUV-SUV } & $D_{\text {Hmin }}$ & $47(14.3)$ & $63(19.2)$ & $78(23.8)$ & $94(28.7)$ & $110(33.5)$ & $126(38.4)$ \\
\hline & $D_{\text {Emin }}$ & $21(6.4)$ & $28(8.5)$ & $35(10.7)$ & $41(12.5)$ & $48(14.6)$ & $54(16.5)$ \\
\hline \multirow{2}{*}{ SUV-car } & $D_{\text {Hmin }}$ & $34(10.4)$ & $45(13.7)$ & $56(17.1)$ & $66(20.1)$ & $77(23.5)$ & $88(26.8)$ \\
\hline & $D_{\text {Emin }}$ & $7(2.1)$ & $8(2.4)$ & $9(2.7)$ & $10(3.0)$ & $11(3.4)$ & $13(4.0)$ \\
\hline \multicolumn{8}{|c|}{ Street-name signs } \\
\hline \multicolumn{2}{|c|}{ Driving distance of target vehicle $[\mathrm{ft}(\mathrm{m})]$} & $50(15.2)$ & $100(30.5)$ & $150(45.7)$ & $200(61.0)$ & $250(76.2)$ & $300(91.4)$ \\
\hline \multirow{2}{*}{ Car-car } & $D_{\text {Hmin }}$ & $33(10.1)$ & $51(15.5)$ & $69(21.0)$ & $86(26.2)$ & $104(31.7)$ & $122(37.2)$ \\
\hline & $D_{\text {Emin }}$ & $29(8.8)$ & $45(13.7)$ & $62(18.9)$ & $79(24.1)$ & $95(29.0)$ & $112(34.1)$ \\
\hline \multirow{2}{*}{ Car-SUV } & $D_{\text {Hmin }}$ & $35(10.7)$ & $54(16.5)$ & $74(22.6)$ & $94(28.7)$ & $113(34.4)$ & $133(40.5)$ \\
\hline & $D_{\text {Emin }}$ & $31(9.4)$ & $49(14.9)$ & $68(20.7)$ & $86(26.2)$ & $105(32.0)$ & $123(37.5)$ \\
\hline \multirow{2}{*}{ SUV-SUV } & $D_{\text {Hmin }}$ & $35(10.7)$ & $55(16.8)$ & 75 (22.9) & $95(29.0)$ & $115(35.1)$ & $135(41.1)$ \\
\hline & $D_{\text {Emin }}$ & $28(8.5)$ & $46(14.0)$ & $65(19.8)$ & $83(25.3)$ & $101(30.8)$ & $119(36.3)$ \\
\hline \multirow{2}{*}{ SUV-car } & $D_{\text {Hmin }}$ & $33(10.1)$ & $52(15.8)$ & $70(21.3)$ & $88(26.8)$ & $107(32.6)$ & $125(38.1)$ \\
\hline & $D_{\text {Emin }}$ & $26(7.9)$ & $42(12.8)$ & $59(18.0)$ & $75(22.9)$ & $91(27.7)$ & $107(32.6)$ \\
\hline
\end{tabular}

difference between the headlamps and the driver's eyes, and the mounting height of headlamps.

The analysis results can be used to help determine whether sign lighting is needed in a certain traffic condition (i.e., considering the potential adjacent vehicles in the stream traffic). In addition, more scenarios can be modelled in the luminance computation model to quantify sign luminance from various lighting sources. However, more work needs to be done in the future research. First, occlusion between vehicles is addressed in the paper but needs to be further included in the luminance computation model. Second, the model calculates sign luminance at a range of distances between the driver and sign, with the consideration of the drivers' detection distance and sign conspicuity relationship at a stationary condition rather than from the legibility perspective at driving status. Additional research is needed to determine the effects of vehicle speeds on drivers' legibility of signs. Last but not the least, luminance is used in the paper as the performance metric of sign sheeting. However, the relationship between legibility or visibility and luminance is a function of surround complexity (glare sources), contrast ratio between the legend and the background, drivers' visual abilities and etc. Therefore, it will be more meaningful to go beyond luminance and assess the legibility or visibility of signs based on drivers' visual demands. The Visibility Level model developed for pavement markings can be extended to model the visibility of traffic signs with the consideration of various lighting sources (Ye et al. 2013).

\section{References}

A Review of KDOT Overhead Guide Sign Lighting Policy. 2011. Kansas Department of Transportation, US. Project Number RE-0549-01.

AASHTO. 2011. Survey Results \& Analysis for JTC on Roadway Lighting - Survey of AASHTO Members December 2010. 39 p. Available from Internet: http://scote.transportation.org

ASTM D4956-13. Standard Specification for Retroreflective Sheeting for Traffic Control. Available from Internet: http:// www.astm.org/Standards/D4956.htm

Brich, S. C. 2002. A Determination of the Appropriateness of Virginia's Retroreflective Sign Sheeting Specification for Fluorescent Orange Construction and Maintenance Signs. Final report VTRC 03-R5. Virginia Transportation Research Council. 40 p. Available from Internet: http://vtrc.virginiadot.org/PubDetails.aspx?PubNo=03-R5

Carlson, P. J.; Hawkins, H. G. 2003. Minimum Retroreflectivity Levels for Overhead Guide Signs and Street-Name Signs. Report No FHWA-RD-03-082. US Department of Transportation, Federal Highway Administration. Office of Safety Research and Development, Turner-Fairbank Highway Research Center. 120 p. Available from Internet: http://www. fhwa.dot.gov/publications/research/safety/03082

Jackson, N. M.; Jackson, G. R.; Carlson, P. J.; Ye, F. 2013. Use of High Intensity Reflective Sheeting in Lieu of External Lighting of Overhead Roadway Signs. Final Report No BDK82 977-07. University of North Florida, US. 82 p. Available from Internet: http://www.trb.org/main/blurbs/169171. aspx

Johnson, N. L. 1999. Reflective sign viewing scenarios using vector calculation methods, in Progress in Automobile Lighting: Proceedings of the Conference. Darmstadt University of Technology, Germany. 
Kleinschmit, M.; Couzin, D. 2008. Evaluation of road-sign geometry parameter space using exact roadway geometry output computer model, in TRB 87th Annual Meeting Compendium of Papers DVD, 13-17 January, 2008, Washington, DC, USA. 11 p. (DVD).

Schoettle, B.; Flannagan, M. J. 2011. A Market-Weighted Description of Low-Beam and High-Beam Headlighting Patterns in the U.S.: 2011. Report No UMTRI-2011-33. 30 p.

US DOT. 2009. Manual on Uniform Traffic Control Devices for Streets and Highways: 2009 Edition Including Revision 1 dated May 2012 and Revision 2 dated May 2012. US Department of Transportation (US DOT). 862 p. Available from Internet: http://mutcd.fhwa.dot.gov/pdfs/2009r1r2/ pdf_index.htm

Woltman, H. L.; Youngblood, W. P. 1976. An Assessment of Indirect Factors Affecting Reflective Sign Brightness. 3M Company.

Ye, F.; Carlson, P. J.; Jackson, N. M. 2014. Use of high-intensity reflective sheeting in lieu of external lighting of overhead roadway signs in Florida, in TRB 93rd Annual Meeting Compendium of Papers, 12-16 January, 2014, Washington, DC, USA. 15 p. (DVD).

Ye, F.; Carlson, P. J.; Miles, J. D. 2013. Analysis of nighttime visibility of in-service pavement markings, Transportation Research Record 2384: 85-94. http://dx.doi.org/10.3141/2384-10 